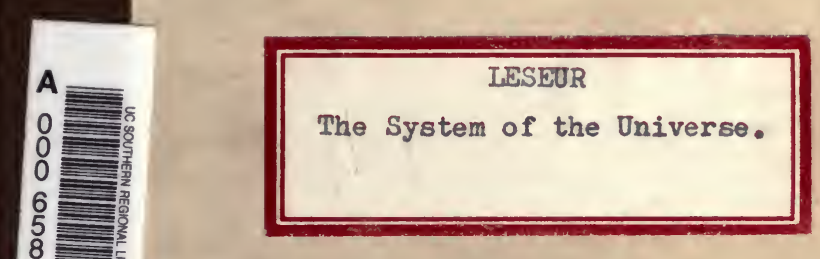

Q

173

L62 



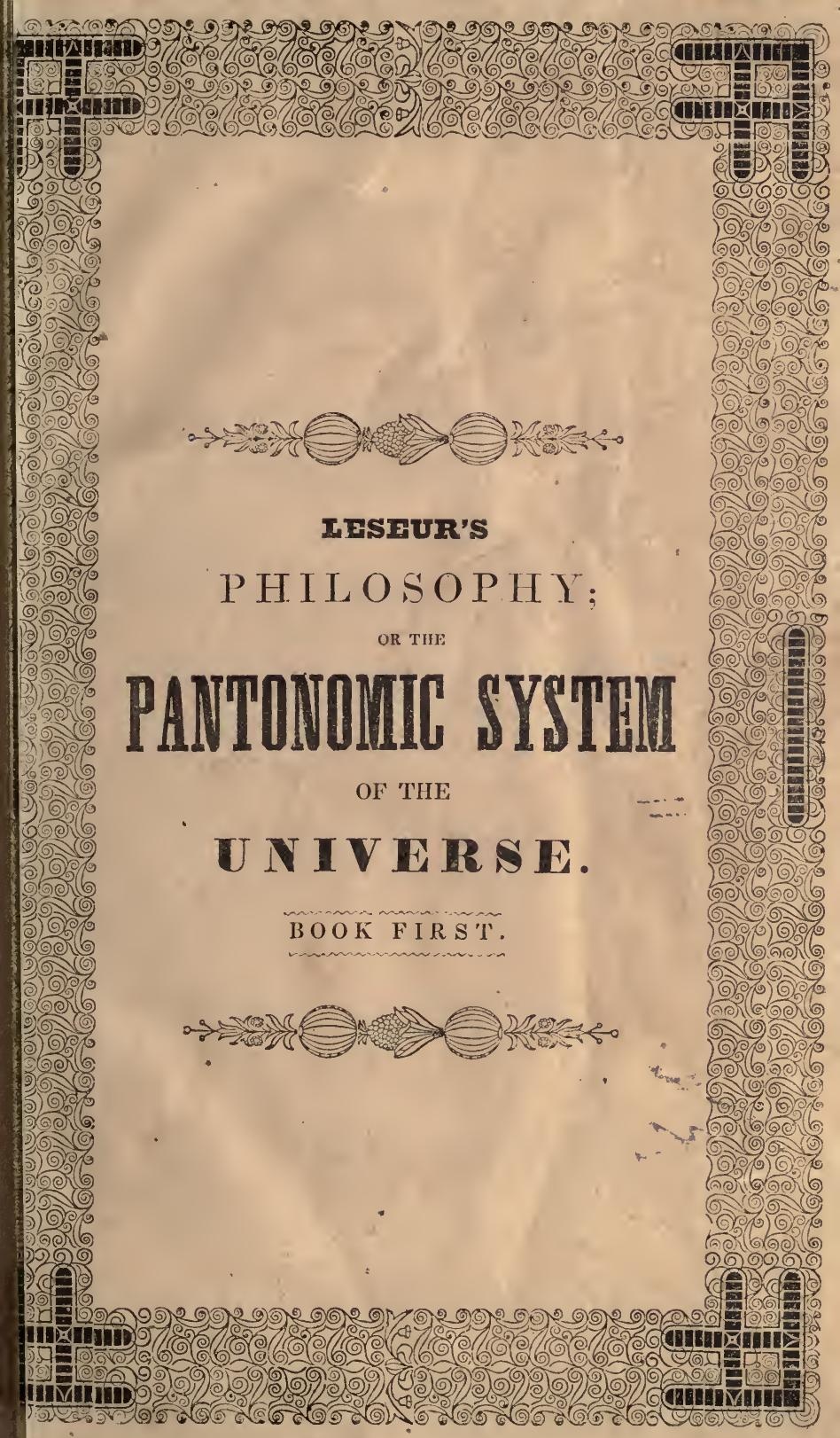





\title{
THE SYSTEM OF THE UNIVERSE,
}

\author{
ExING A
}

N E W S Y S T E M

\section{CHRISTIAN PHILOSOPHY,}

CONTAINING A COMPLETE EXPLANATION AND CLASSIFICATION OF UNIVERSAL SCIENCE, FOUNDED UPON UNCHANGEABLE LAWS AND EMBRACING WITHIN ITS FORMULE EVERY DEPARTMENT OF HUMAN INQUIRY.

CORRECTED FROM THE ORIGINAL DISCOVERY,

MADE BY

FRANCIS IESE R, IN 1831 .

PUBLISHED FOR SUBSCRIBERS.

H A R T F OR D.

Printed by J. Gaylord Wells, 184 1.2 Main Street. 
ENTERED according to Act of Congress; in the year 1840, by FRANCIS LESEUR, in the Clerk's office of the District Court of Connecticut. 


\section{SANIA BARBARA \\ THE SYS'TEM OF THE UNIVERSE.}

1st SOURCE OF ACTION.

DIVINITY.

1 st.

$2 d$.

3d.

1. CREATOR.

2. MEDIATOR.

3. RELATIVE POWER.

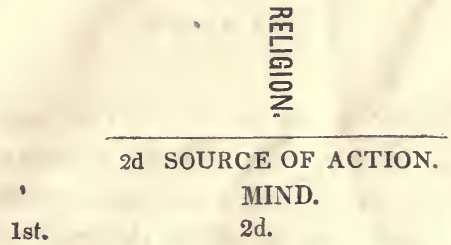

$3 d$.

4. INTELLECTUAL. 5. MORAL. 6. SENSITIVE POWERS.

7. 1. Intuition.

8. 2. Reason.

9. 2. Imagination.

$\mid \begin{aligned} & \text { 10. 1. Duty to God. } \\ & \text { 11. 2. " our fellow being. } \\ & \text { 12. 3. " to ourself. }\end{aligned}$

3
$\frac{1}{I}$
$\frac{1}{3}$
$\frac{1}{8}$
0
13. 1. Love and hatred.

14. 2. Joy and sorrow.

15. 2. Fear and courage.

Connected with matterby hearing, seeing and feeling sound, color, form.

3d SOURCE OF ACTION.

\section{NATURE.*}

Ist.

$2 d$.

3d.

16. ORGANIZA TION. 17. CALORIFIC MOTION. 18. MATTER,

19. 1. Animal.

20. 2. Vegetable.

21. 3. Mineral.
22. 1. Combustion.

23. 2. Electricity.

24. 3. Magnctism.
25. Solid.

26. Liquid.

27. Aeriform.

The above is the complete order of the universal Triune, or circle.

The following is a continuation of the subdivisions in the third Source of action, or material circle, beginning with the highest state of organization. This being the first subdivision under the organic circle.

\section{ZOOLOGICAL CIRCLE, OR ANIMAL KINGDOM.}

HUMAN RACE.

1. Caucasian.

2. Mongolean.

3. African.
LOWER VERTEBRATA.

1. Quadrupeds.
2. Birds.

2. Birds.
INVERTEBRATA.

\begin{tabular}{|l} 
1. Annulosa. \\
2. Radiata \\
3. Mollusca.
\end{tabular}

* All changes in nature are produced by motion - there are three kinds of motion, 1st, ealorific or primary, produced by relation of elements. 2d, relative or mechanical, produced by contact of bodies. 3d, Organic motion. 



\section{P R E F A C E.}

Is presenting this volume to the public, nothing need be said more than to mention the object of its publication.

Ten years have now passed away, since the System of the universe was discovered; at the commencement of this period, a small and imperfect explanation was published, with a promise to give a full exposition of the theory, as soon as practicable. But unfavorable circumstances soon followed, which prevented all further publication.

The object of the present work is to give a complete explanation of the primary principles of this System, and to show the application of it to the more practical and useful branches of science, in relation to the advancement of human knowledge, as well as to the higher investigations of all science in connection, as displayed in the perfect laws of the Creator, developing one great system of universal order and harmony.

Hartford, January, 1840.

The synupsis on the third page gives an analytic view of the first great divisions of science, and will be fully explained, together with a more extended analysis, in the following work. 


\section{"FOR THE INVISIBLE THINGS OF HIM FROM THE CREATION OF THE WORLD ARE CLEARLY SEEN; BEING UNDERSTOOD BY THE THINGS THAT ARE MADE, EVEN HIS ETERNAL POWER AND GODHEAD."- ROMANS, I. 20.}

"In primis, hominis est propria veri inquisitio atque investigatio. Itaque cum sumus negotiis necessariis, cuvisque vacui, tum avemus aliquid videre, audire, ac dicere, cognitionemque rerum, aut occultarum aut admirabillinm, ad bene bcateque vivendum necsssariam ducimus ; - ex quo intelligitur, quod verum, sirnplex, sinccrumque sit, id esse naturæ hominis aptissimum. Huic veri videndi cupiditatis adjuncta cst appetitio quædam principatus, ut nemini parere animus bene a natura informatus velit, nisi præcipienti, aut docenti, aut utilitatis causa juste et legitime impranti : ex quo animi magnitudo existit, et humanarum rerum contemtio."-Cicero, de officiis Lib 1 . $\$ 13$.

Before all other things, man is distinguished by his pursuit and investigation of truth . And hence, when free from needful business and cares, we delight to see, to hear, and to communicate, and consider a knowledge of many admirable and abstruse things necessary to the good conduct and happiness of our lives: whence it is clear that whatsocver is true, simple, and direct, the same is most congenial to our nature as men. Closely allied with this earnest longing to see and know the truth, is a kind of dignified and princely sentiment which forbids a mind naturally well constituted to submit its faculties to any but those who announce it in precept or in doctrine, or to yield obedience to any orders but such as are at once just, lawful, and founded on utility. From this source springs greatness of mind and contempt of worldly advantages and troubles. 


\section{PANTONOMY,}

GENERAL REMARKS.

Tnere is a difference between the effects of local and general knowledge, and there is a wide difference between that isolated knowledge of facts, or arts, which the world calls practical, and those universal principles of science upon which all art as well as knowledge must depend for its correctness. Aided by the advantages of the former, it is in this latter sense that knowledge becomes the true source of progressive improvement and happiness, and lays a permanent foundation for moral and religious truth on the firm basis of the physical and exact sciences.

Wherever an increase of this knowledge is introduced, its enlivening influence upon the character and condition of society is no less certain than that of the rising sun upon material creation. At the approach of the latter, animal and vegetable nature seem to expand with additional life and activity; they not only feel his direct power, but they become expanded with capacity to receive additional nourishment from the surrounding earth and atmosphere, and the influence also extends far beyond the objects immediately affected, for they become relatives by which other objects are energised, the reflected rays are thrown out in all directions from object to object and even far into the shade, so that all things reciprocate the general influence; the proper materials of life are transfused throughout material organization - music is heard in the grove - beauty and incense come forth from the unfolding flower; all the variety of colors are displayed and even the cold mineral shines with a dazzling lustre. And thus it is with the mind at the approach of science, for its influence cannot be confined-it will impart an invigorating power to all within its reach, 
the faculties of the mind become expanded, capable of receiving additional happiness - each individual becomes the source of happiness to those around - the rays of truth are reflected from mind to mind until a gradual change is wrought in the intellectual, moral and physical condition of the community - superior order and taste appear in the external character and refinement, benevolence and happiness shine from within.

Scientific truth, where it has not been suppressed, has ever proved a powerful aid to the precepts of Christianity, and it is these combined truths which have been the primary source of all those high blessings which distinguish civilized man from the heathen world. If the word of God is " a lamp to our feet and a light to our paths," it is the knowledge of science which is to extend the mental vision until we are enabled to behold the light in all its beauty and splendor. It is science which has enlarged our capacity for making use of the divine precept, and of extending its influence throughout the world, reason and faith are here united. "The tree of knowledge is grafted upon the tree of life, and that fruit which brought the fear of death into the world, budding on an immortal stock becomes the fruit of the promise of immortality."

The term Philosopher is formed by the connection of two Greek words, and signified, originally, a lover of learning or a lover of knowledge. It comes down to us from the earliest ages of Grecian history, and it would be difficult to determine who first claimed the name, or who first deserved it. The name Philosophy was originally applied to the writings or instructions of those who observed and studied the operations and general laws of nature, compared the principles thus obtained with the few facts they could collect from their limited knowledge and handed the result of their investigations down to posterity. While the art of printing was unknown, they had no other way of communicating their knowledge to others, to any extent, than by establishing schools, hence the various schools of Philosophy among the ancients, many of which existed many years before the Christian era. Plato, Aristotle, Democratus, Epicurus and Zeno were all distinguished as teachers of their own peculiar doctrines; but 
they seem to have labored under the same difficulties with most of their successors. They wanted an unchangeable and universal law of science, on which to predicate their doctrines, and which might guide them in all their researches. This difficulty has existed in all ages. We see men of genius taking up detached branches of science and examining them according to their own practical observations, or the observations of others, without regard to the relations which one subject of science bears to another in the great scale of human knowledge. While others of more general observation but equally unsuccesssful, are wandering about in the dark in the great field of science, until they are lost and bewildered by their own speculation, like the marine who would attempt to navigate a vast and unkown ocean without a chart, a compass or a pilot.

It would be foreign to the present subject to enter upon an examination of the merits of any writings, either ancient or modern; but it may, however, be remarked, that a large amount of prejudice has existed in conscientious minds, both in this country and Europe, against works professedly philosophical, and for this they have had very good reasons : for many who have pretended to write on the subject have run into such extremes of Skepticism, Idealism and Materialism, as to give a direct tendency to infidelity. This fact, however, forms no objection to a correct system ; but on the contrary shows the necessity of one that will explain those laws which are the foundation of all philosophical truth, and without a general knowledge of which, we may expect always to be troubled with false theories. Religion has had its false teachers in almost every age since the commencement of Christianity; yet there is but one true code of Christian laws; and is it not probable that there is but one true system of Philosophy? 


\section{EXPLANATION OF TERMS.}

Is entering upon an explanation of the present system, the author is fully aware of the difficulty arising from the use of terms which are not definitely understood. But as the name of a thing does not constitute its quality, so it must be remembered that the name of a branch of scierice does not explain it, and it is deemed sufficient for the present purpose, without adopting a special nomenclature, to use such terms as are best understood according to common acceptation, and in so doing some repetition must necessarily occur.

There are few words in our language that have been used in a more general and unlimited sense than the term science. Considering its Latin derivation it seems nearly synonymous with knowledge, while modern usage has confounded it in many instances with the meaning of the word art. An individual highly distingished for his learning, and known in this country as a man of science, while lecturing on natural philosophy a few years ago, gave the following definition: "science may be considered as an art or the result of an art."

Another has lately said, while lecturing, "science is knowledge reduced to order."

Herschel, the great European philosopher, says, "science is the knowledge of many, orderly and methodically digested so as to become attainable by one.

Bacon says, "science is being awake." Now from all this explanation we have no correct idea of what is meant by scicnce.

The term as used in the present system may be explained as follows :

It stands here to represent all the different departments of human inquiry into which the laws of the universe are divided, each division forming a necessary part of the great whole - the laws of analysis - of division and subdivision which run throughout, define the relations which each part bears to all the others, and brings all branches of science into one great system of order 
and subordination of parts. From this consideration we perceive that science includes all the laws of the universe collectively, and those of each branch separately. As the Creator has thus placed all things in certain relations to each other, the true character of these relations must depend on the situation of each part in regard to the whole, as well as in regard to each particular part more immediately associated with it. In our systematiçinvestigations, we must therefore follow the true law of classification, (and not an artificial arrangement,) and, accordingly, it is evident that science, in its most extensive sense, is the law of the universe. This is its definition. Law is a rule of action or arrangement. What is the universe? Under this term we include all that we know or are capable of knowing - all that we perceive or are capable of perceiving, while in the present state of existence. Should this world stand for millions of ages to come, the laws of science once known would remain unalterably the same, and that system which arranges and classifies them, if it be a true one, must remain the same that it now is. It is true, man may invent by applying any of those known principles to any new, useful, or amusing purposes of life, thus instituting new arts, and the knowledge of such a system must, in this respect, be of great service to him by pointing out new arrangement in the laboratories of nature which he might not have thought of without it.

We have now explained what, to us finite beings, is the universe, although to beings of higher intelligence it may be but a part, and to God it may be but an infinitely small part, yet to man, in his present state of existence, it must ever be the whole uni. verse.

The numbers $1,2,3$, as used in the synopsis, indicate the primary divisions of science, or any one of the branches or subbranches.

The word nature is perhaps used in a different sense here from what we have been accustomed to see it in other works. By referring to the general synopsis, it will be found to include under it all the laws of the; material world, and nothing more 
than these; and although we may have been accustomed to speak of the nature of the mind, and the nature of the divine attributes, this term has been selected as the least objectionable.

The term organization is placed over the three kingdoms of nature, the animal, vegetable, and mineral, and includes, as this system requires, all the laws belonging to them under one head. Although this term has been applied exclusively to the two former, while the mineral kingdom has been termed inorganic, thcre is good reason, as will be hereafter shown, for designating them all under one general name, applying to all bodies gradually assuming peculiar forms under distinct laws. Vegetable formations differ quite as much from animal formations as those of the mineral kingdom do from vegetation. The earth, independent of animal and vegetable matter, is as truly an organism as the human body, and yet the atmosphere, water, and earthy substances, of which it is composed, are all mineral.

By the term, calorific motion, as used in the synopsis, is not meant any one of the sensible properties of fire, such as heat or light, but the primary cause of them all.*

By the analytic process is meant the dividing and sub-dividing of a whole into its various parts or ultimate elements.

By the synthetic process, we take the reverse sequence, re-uniting the parts in their order till we have formed them into one. In every perfect organism, or system, there is a law of relation and subordination of parts running throughout, which we must follow analytically or synthetically, if we would understand the system.

Now, it is evident that without this process any one may form imaginary divisions, and from them an imaginary or artificial classification, applying to any known branch of science, such, for instance, as the animal kingdom, or a class of vegetable forms ; and he may even found his arrangements upon some supposed or real resemblances. A great many such attempts have been

*'The divisions of motion are organic, mechanical, and calorific-calorific motion will be divided into combustion, electricity, and magnetism - and combustion into heat light, and chemical rays - electricity into positive, negative, and neutral force, which, under the name of magnetism, becomes contripetal, centrifugal and tangental motion. 
made, and artificial classifications have been formed, many of which have been laid aside as soon as formed, giving place to others equally visionary and short lived. But it should be remembered that even artificial systems when founded on real resemblances and relations; like those of Linnæus, have had their advantages, and have often brought to light new relations and new facts, which were unknown before; and thus having answered their purposes they have passed away, leaving, perhaps, little to be remembered of them in after times, except the praiseworthy exertions of their immortal authors.

It is not necessary here to enter upon a consideration of the various attempts at systematizing. There has always been a tendency in philosophic minds to generalize the laws of nature, and to render more intelligible those abstruse principles which have proved uninteresting to the ordinary student. But all the systems which have been attempted, seem to be more or less local or artificial, extending, in general, only to a few branches of natural science; or if, as in some few instances. a wider range has been taken, the obscurity in which they have heen involved, seems to increase in proportion to the extent of survey.

Among those whose minds have been employed on this subject, stand conspicuous, the names of Linnæus, Lister, Willonghby, Ray, Lamark, Latreille and Cuvier. The labors of these great naturalists were confined almost exclusively to a few branches of natural science included in the animal and vegetable kingdoms, yet they shed additional light over the whole field of nature, while, perhaps, neither of them thought his classification would remain long unchanged. Even Linnæus, whose writings have been more highly approved, and circulated farther than those of any other naturalist, left us nothing more than an artificial classification, and no one ever felt more the deficiency of his system than himself; for, while he acknowledges this, he invites Philosophers engaged in botany, every where, to make common interest with him in seeking for a natural system, by which he undoubtedly meant a system founded upon fixed laws, and remaining unchangeable in all its arrangements. 
How far this spirit of systematic inquiry has prevailed among those engaged in other departments of science may be inferred from the fact that it has been carried into the more hidden recesses of nature, bringing to light chemical relations, and laws of definite proportions which were before unknown. Of this, we have ample proofs in the discoveries of Wollasten, Dalton, Ritter, Herschel, Bechman and Davy. But, unfortunately for the world, systematic inquiry has not only been deficient, but it has been confined almost exclusively to natural Philosophy, leaving moral and intellectual science unimproved by its aid. Are not our physical improvements far in advance of our mental resources? Where are our rail-roads to moral and intellectual knowledge? Why should not all our institutions of learning - all our schools be raised to higher standard by a new impress from the advantages afforded by additional knowledge of the laws of science? The laws of moral and divine science are no less certain and definite than those of the material world. What has already been shown to be true in this respect, in relation to the things of visible creation, are also true of the invisible powers of mind. There is a true system of all things; and the writer would ask indulgence while he adds a few extracts to the present digression from the main subject, to show that such a system, as is here proposed, is not inconsistent with the hopes indulged by wellknown authors.

Herschel, in his discourse on natural history, says :

"It can hardly be pressed forcibly enough on the attention of the student of nature, that there is scarcely any natural phenomena which can be fully and completely explained in all its circumstances without a union of several, perhaps all the sciences."

De Candolle, in his introduction to botany, says:

"It ought to be most zealously inculcated, that the application of this science should only be taught or learned after a previous study of general principles," thus making a knowledge of general laws necessary to a right understanding of local and practical science. 
Mrs. Somerville, in her work on the material sciences, says :

"Perhaps the day may come when even graritation, no longer regarded as an ultimate principle, may be resolved into a yet more general cause, embracing every law that regulates the material world."

And again, speaking of discoveries, she says :

"The experiments made on light, heat, electricity and mag. netism, show an occult relation between all these agents, which probably will one day be revealed, and in the mean time it opens a noble field of experimental research to Philosophers of the present, perhaps future ages."

Wiseman says, in his work on Philosophy :

"Were it given unto us to contemplate God's works in the visible and in the moral world, not as we now see them in shreds and fragments, but as woven together into the great web of universal harmony ; could our minds take in each part thereof with its general and particular connections, relations, and appliances, there can be no doubt but religion as established by Him, would appear to enter and fit so completcly and so necessarily into the great plan as that all would be unraveled and destroyed if by any means it should be withdrawn."

\section{ANALYTIC VIEW OF THE SYSTEM OF THE UNI-}

\section{VERSE, EXPLAINING THE SYNOPSIS - PAGE 3*}

By referring to page third, we find all things united under one great head, the Deity. He is all in all ; and from this Source, we begin to classify, descending analytically to the most distant and subordinate parts, according to the theory of division and

\footnotetext{
- I cannot hope to give every one a correct idea of this important subject, by merely reading it over once, for we have here assuciated together subjects which, perhaps, have been by many always considered as entirely distinct : perhaps it requires tou great exertion of the mind, at first, to transfer itself from the Divine to the mental world; and then again from the spiritual and invisible powers of mind down to the tangible things of ma. terial creation. But if we would understand science, we must accustom ourselves to this wide range of thought; we must see the little and the great, if we would bear even a faint resemblance to $\mathrm{Him}$ who sees all things in their true relations, and Who, while $\mathrm{H}_{0}$ directs worlds and systems of worlds in their course, permits not a sparrow to fall to the ground without His notice
} 
sub-division. 'The three first great divisions, whose union constitute what may be called the universal circle, are, Ist, Divinity ; 2d, Mind; 3d, Nature. These stand in the order one above the other, indicating different degrees of importance attached to the subjects to which they relate; the second being as far below the first, as the third is below the second ; and they may be considered as three distinct worlds, connected by laws of analogy and relation. It will be observed, however, that religion is included as a relative branch between the first and sccond, and mathematics between the second and third.

In the first of those great divisions, the Deity is the source of action; in the second, thought, or intelligence, is the source of action; in the third, calorific motion is the source of action. In mentioning these sources, it must be remembered that Deity is the primary source of all actions resulting from the laws of science, (sin being merely an unsuccessful attempt to evade these laws; and thus moral evil being the result of such attempts can not be chargable in any way to the Deity as a cause of its existence.)

According to the order here established, the first subject of science to be considered is that which relates directly to divinity. This department is called theology, and includes all that we know of God, of his relation to us or to the material world, either by divine revelation, by natural religion, or by the indications of design in the works of creation and providence.

The second department belongs to mind or human intelligence, and includes the laws by which the minds of all created intelligent beings are governed. This department is called mental science, or psychology, but in accordance with the present system it should be called psychonomy.

The third department belongs to nature and includes all the laws of the material world. It may be called material science or physiconomy.

In the theological department, the first of the triune relations, refers to the Creator, the second to the Mediator or Son, the third to that power which stands in immediate relation to the mind of 
man; i. e., the power or holy spirit by which the mind may hold communion with the divine world, having access throngh this power to the mediator, and through him to the Father or Creator, thus the divine trinity may be explained by reference to these three degrees of relation to the mind of man, which are united in one God.

The sub-divisions of the mental department are, 1st, the intellectual, $2 \mathrm{~d}$, the moral, $3 \bar{d}$, the sensitive powers of the mind of man, each of which forms a sub-branch of science, yet they are united, three in one, constituting the mind. The sensitive powers are nearest to the material world, and are the medium through which the higher powers hold communion with nature. These three degrees in the human mind, and the order of its relation to matter, are a resemblance of the divine trinity and its relation to the human mind. "God created man in his own image."

The department including the material or natural sciences is sub-divided into organization, motion, and matter ; these primary properties of nature are also united in one, and cannot be seperated without destroying the laws of the material world.

None of the sub-divisions here enumerated can be explained separately, although we must, in order to understand science, direct our attention to each one of them so far as to make it a leading object of study, considering the laws of its internal parts, as well as those by which it is related to other divisions, forming with it larger branches. This must be understood in regard to all branches of science, whether large or small - whether they have been divided into few or many parts - they are all related, and if the divisions are in accordance with this system, there will be no difficulty in seeing their true relations; and thus it is clear that no one science can be properly understood without some general knowledge of the whole range.

It will be seen, by looking to the synopsis, that religion stands between the mental and divine departments, and it was called in my first publication a relative science, to distinguish it from those branches which were called sub-divisions of principal branches.

It is the true Divino-Mental Science, and its place clearly defined, whether it be called a relative or compound science. 
Its first sub-divisions have reference to the three states which are connected with the great principles of moral and religious duty, as recognized by the mind. The first is the heavenly or divine state; the second is the earthly or probationary state; the third and the lowest extreme, is the state of woe - where the consequences of sin are to be suffered.

Mathematics alsu stands between mind and nature, and might be called the mento-physical science. Its elementary principles are, addition, deduction, and division. It is the medium by which the mind takes cognizance of the relative and true proportions, properties, arrangement and powers of all material things; applying it also to the arrangement and analysis of its own powers; thus it applies to mind and matter. It furnishes us with the only real test of truth in regard to the material world, while true religion furnishes a test of truth in regard to things pertaining to the divine world.

The entire foundation of mathematical science rests on the simple principles of addition, deduction, and division. The most abstruse branch, even the Deferential Calculus of Newton, contains nothing more than the application of them under more complicated arrangements. We have no idea of addition without deduction, nor of deduction withont addition, nor of division without both. This same law is represented by the primary divisions of time. We have no idea of the future without the past, nor of the past without the present and future.

Ilaving shown the first sub-divisions under the three original departments, or principal sciences, we lave nine leading branches and two compound branches, the divino-mental and mentophysical. Now, all the different subjects of inquiry which the mind of man can reach are included within these; being combinations or applications of the true principles contained under them. All minor branehes being divisions from them as they are from the first three.

I have now explained the universal circle of divinity, mind and nature, as far as the first degree of analysis, and from this we may proceed downward by the same process of division and sub- 
division, leaving each superior branch of the last circle, when we have divided as far as the subject may require, and proceeding to the lower, or next in order, and thus continuing to the most remote parts - to simple and individual elements; the classification is the same, however far it is carried - all branches are connected, each occupying its own proper place.

From the preceding general view of the subject it will be seen, firstly, that this system does not require, as some have supposed, that every thing should be divided into three parts. But it seems to prove that the mathematical arrangement here proposed, furnishes the only correct formulæ that will apply to the primary divisions and classification of universal science. This formulæ, requiring that the first divisions in every combination forming unity in the laws of science, should be made out by reference to two extremes and a medium as the only correct data for investigation. In applying this data to the analytic divisions in the consecutive and proper order, in any succession of beings, or organisms or parts of an organ, as arranged by the Great Author of all, one and the same rule is required, viz: the most important, the most complex, the most perfect hranch, (if we may use the term where every thing is perfect in its place,) constitutes the first extreme in all cases, and the lowest - the most elementary - the most simple branch, constitutes the last extreme, while the intermedium occupies the place between, being as much below the first as it is above the last. Now, each of these contains its own particular extremes and medium when considered separately. The process may be compared to that which takes place in the separated pieces of a magnet, where each piece assumes the extremes of opposite polarity with an intermediate neutral space - thus continuing in all respects like the original large magnet from which they were broken, being divisions from it. 
And, 2dly, having shown this uniform subordination of parts we observe that in the true order of creation, the most simple, or elementary, is the first in order of time, and the most perfect the last; this being the synthetic order, is the reverse of that laid down in the synopsis, page $3 \mathrm{~d}$, and is easily explained by turning to it and casting the eye upon the $3 \mathrm{~d}$ part under the term nature, which is the 18 th from the beginning - it being headed matter, and divided into solid, liquid and æriform. The æriform branch being the last, is the most simple in the scale there given and admits of but one degree more of analysis, by dividing it into oxygenious, hydrygenous, and etherial elements. These are the true ultimate elements of matter, by the relations and combinations of which all material bodies are composed. These simple elements constitute the materials of which the sun and all the planets of the solar system are composed, while they enter into and constitute the materials of the smallest organized bodies that grow on the earth. These three kinds of matter operated upon by the three kinds of motion - calorifie, mechanieal, and organic, produce three kinds of organization, viz : mineral, vegetable, and animal, thus constituting the whole material world.

The process of creation, as stated above, must be traced synthetically to accord with the order of time; thus we begin with these simple elements, of the origin of which we have no idea, except that they are under the dominion of the Creator. Whether he created them out of nothing, or whether they have ever existed as the vestments of Him who inhabiteth eternity, belongs not to the human mind to inquire. Our legitimate inquiry begins with the embrionic formation of the present material world. 'The first division is the mineral kingdom. Its formation commenced first in order of time. Its 1st synthetic divisions are,1st. primary strata ; $2 \mathrm{~d}$, transition; $\mathbf{3 d}$, that which has been called secondary strata. The next kingdom in order of time is the vegetable. it had its formation in and grows up out of the mineral kingdom, and is inseparably connected with it. Its divisions are, 1st, annuals, or plants ; 2d, endogeneous ; $3 d$, exogeneous 
trees. The next in order of creation is the animal kingdom, which has its foundation in the vegetable. Its 1st divisions are seen in the synopsis, placed in the analytic order.

$3 \mathrm{dly}$, these great departments in the organic circle, are distinguished from each other, not merely by their outward forms and properties, but also by their internal structure, as follows: Minerals are formed by simple geometrical laws of chrystalization. Vegetation is formed by the union of the laws of chrystalization, with the vegetative principle; while every being in the animal kingdom, unites in itself the laws of chrystalization, vegetation, and sensation.

4thly. We have now shown that nature consists of three distinct kinds of organism, each possessing different degrees of perfection, and that each, though complete in itself, is connected with the others, and each becoming more perfect as we arise in the scale of material beings; and as the human race is the highest extreme in these organic sciences - the human body being the most perfect of all material organisms, we might expect that a still higher principle had its development in it; and such inference is correct, for the human mind is a spiritual organism.

5thly. In the true science of Antroponomy, the same arrangement applies. Man is first considered in his material or natural state. He is first a material organism ; to this is added the mental, life or spirtual, organism ; and lastly, to these two, the divine life, each successive development depending on the perfectness of the preceding state; thus a good and healthy mind depends on a proper development of the bodily organs, particularly the cerebral development ; and thus it follows again that in the divine life we shall be happy or miserable in proportion to the proper or improper use we make of our mental powers while in the present state of existence.

6thly. From the preceding considerations we see that man is not only represented by the three kingdoms of nature, but is himself a sub-typical representation of the whole range of pantonomic science. This law of representation runs through all branches of science. 
7thly. In all dynamical science the true data consists of cause, power, and effect. The extremes, cause and effect being known, the relation between them which is here called power, can be traced out. By referring to page $3 d$, it will be seen that calorfic motion is the first moving principle in the material world; and, therefore, all effects under the laws of nature, however far they may be removed by chains of intermediate relations, must have their origin in this cause. Thus every effect in nature originates from colroic. Every cffect in the mental world, under the laws of mind, originates from intelligence. Every effect ahove these is superhuman and supernatural - it is from the immediate intervention of divine power, and, consequently, a miracle.

This theory being established, the process may be carried either way - from cause to effect or the reverse - cause and effect depend on time in regard to their natural sequence; for an effect becomes a cause when considered in relation to other effects which result from it, being connected postcedently with it, and vice versa - a cause becomes an effect when considered in relation to its proper antecedent. The most common order of inquiry is from effect to cause. An effect must always be experienced before there is any idea of a cause ; the cause having operated antecedently, for it is certain that they cannot commence at the same instant, alihough they may appear simultaneously ; thus we may trace back from effect to canse througl all their relations until the inquiry terminates in one of the sources of action above named.

T'he connection between cause and effect is called power thus power always implies relation, for one thing can never affect another unless it be in some way connected when associated with it. Relation implies difference between cause and effect. Difference implies superiority and inferiority; the cause being the superior, or first in time - the effect, the inferior, or last in time. These being connected by the relative power, constitute the natural sequence called cause, power, and effect.

All created things are the effect of which the Almighty Creator is the cause ; and the intelligent act of creating and preserving 
them in existence, forms the relation between Him and His works ; and we find that this natural sequence exists throughout creation - having originated from the first act of Deity in creating all things, it constitutes the first principles of all dynamical science.

\section{PRACTICAL ILLUSTRATIONS OF THE GRAMMAR OF SCIENCE.}

The analysis given on the third page, does not extend so far as I intended; but some further idea of the extent and perfect arrangement of the system will be obtained from the following review.

Suppose a student who is studying Botany (perhaps he is counting the stamens of a flower to find its place in the Linnæn system) should be asked what branch of science he was engaged in, where does it belong? What are its relations to other branches of science? What place does it occupy in the great field of nature? or in the still greater field of universal science? What is the answer? Is there any rule in any Philosophy by which this question can be answered? By referring to the synopsis, we find it occupies the $2 \mathrm{~d}$ place, and is the medium branch in the organic circle, standing between the animal and mineral departments - the one being the first extreme, and the other the last - and it runs imperceptibly, like the colors of the rain-buw, into both, and is connected indissolubly with them.

This is its foundation - let us trace it to its origin. It is the $2 \mathrm{~d}$ in the organic circle - the organic is the first in the natural - and the natural is the $3 \mathrm{~d}$ in the universal circle, and consequently this branch is the 20 th remove from the beginning.

We will now take the science Entomology. This branch explains the nature of insects or the Annalosa order. This is the 1st division in the invertebrated circle called the Annalosa - it is the 1st extreme and connected with the Radiata, which is the $2 \mathrm{~d}$ part of the same circle. Thus it is the 1 st in the invertebra- 
ted circle - the invertebrated is the $3 \mathrm{~d}$ in the zoological - the zoological department is the 1st in the orgabic - the organic is the 1st in the natural, and the natural is the $3 \mathrm{~d}$ in the universal.

Suppose a student is studying moral Philosophy, and we put the question, What is the foundation of this branch of science? The answer is, It is the $2 \mathrm{~d}$ part in the mental department. And this again is the 2d part in the universal. Now suppose the student has been reading a sentence, and we select a word from it, and ask him what part of speech it is ? He would probably give the name of it and show its relation to other parts of speech or other words in the sentence, giving it a full explanation - for if he had even the advantages of a common education he would not like to be thought ignorant of the grammar of his native language.

But did he ever stop to think that every sentence he reads has reference to some one or more branches of science, and that that branch has an appropriate place in the scale of science, and a name and relation as much as any part of speech has a proper place in the science of language; and it is possible the time may come when the student will be as anxious to understand correctly the grammar of science as he now is to obtain a correct knowledge of the rules or laws of his language. The time was, a few centuries ago, when the world got along very well without a knowledge of the grammar of language, but it is now considered indispensable, and so it may eventually be in regard to the laws of universal science.

We will now carry this process out into the more minute parts of creation, taking specimens from the animal kingdom. We will trace synthetically the little bird known by the name of the hedge sparrow (Parus Biarmicus of naturalists.) It is the 9th remove from the great circle of the animal kingdom. It belongs to the sub-genus, Parus Proper ; this little circle is sub-divided from the Genus-Parus - Parus is a division from the sub-family Parianæ-Parianæ is a division from the Family Sylviadæ Sylviadx is a division from the tribe Dentirosters - Dentirosters is divided from the order Insessores - Insessores is the 1st divis- 
ion in the circle of Birds - the circle of Birds is the $2 \mathrm{~d}$ in the lower Vertebrata-the lower Vertebrata is the $2 \mathrm{~d}$ in the Zoological - the Zoological, or Animal, is the 1st in the Organic - the Organic is the 1st in the Natural - the Natural is the $3 \mathrm{~d}$ in the Universal.

I will now descend still lower, and take the beautiful Shell Harpula, (Vexillum.)

It belongs to the sub-genus, Harpula Proper. This is subdivided from the genus, Harpula; Harpula is from the sub-family Volutinæ; Volutinæ is from the family, Volutidæ; Volutidæ is from the tribe, Zoophaga ; Zoophaga is from the order, Gasteropoda; Gasteropoda is fiom the class, 'Testacea ; Testacea is from the sub-kingdom, Mollusca; Mollusca is the $3 \mathrm{~d}$ is the Invertebrata; Invertebrata is the $3 \mathrm{~d}$ in the Animal circle; the Animal is the 1st in the Organic; the Organic is the first in the Material or Natural; the Material is the $3 \mathrm{~d}$ in the Universal.

Here I have used the terms, kingdom, sub-kingdom, class, order, tribe, family, sub-family, genus, and sub-genus, because they are terms most familiar with naturalists. Yet all that is meant is a distinct department which has a greater resemblance between its internal parts, than it has to any other department in the whole range of Science. It matters not whether it is called a circle, a class, family, or genus, provided we understand the true order of arrangement.

All these terms - the terms genus and species in particular are in common use among students, yet in the present state of knowledge, they have no definite meaning whaiever, and might as well be entirely discarded. Some speak of the human race, others of the human species; some divide species into varieties; others consider varieties as species. Des Moulins, a French Philosopher, asks the question, "What are species?" but does not answer it. And a late writer says, "that naturalist would be canonized who should answer it in "a manner acceptable to all." Now, whoever will take the trouble to learn the system of the universe as here developed, will find no difficulty in giving a definite and satisfactory meaning to these terms, if they choose to place them in this mathematical arrangement. 
By the analytic process, we find that each circle, or department, according to its superior rank, embraces all those that are below it. Beginning with the circle of the universe, we traverse twelve circles before we arrive at the small animals, whose stations we have just considered, and whose relations have been traced in the opposite direction by the synthetic process till they terminated in the circle of the universe, where all things unite in one great whole. For we proceed from the absolute unity of all things down to the last degree of analysis; and if it is supposed that we have not yet arrived at the last degree of analysis, that is, (when applied, for instance, to a group of animals,) the highest degree of resemblance - that point where no distinction except that of individuals can be found ; then it is evident we must begin at the first extreme, and take the course of analysis; so that we are never without data from which to begin our arrangement ; and if the data be fixed, and the series uniform, every sub-division will be equally fixed and certain, and show its precise situation in the great scale of science.

\section{KNOWLEDGE PANTONOMICALLY CONSIDERED.}

Having now given a complete prodromus of the system of the universe, I shall for the sake of illustration make a few observations on different subjects, without taking up the sciences in. order.

It is claimed that the world is rapidly increasing in knowledge at the present day. If this be true, we must admit one of two things; either that human knowledge is a positive evil, or that we are not progressing in the right kind of knowledge; for no one who takes a correct and impartial view of the present moral state of society, can doubt that there is a deficiency in moral worth, and consequently in true piety, which ill compurts with our apparent advantages.

Now science proclaims that knowledge in its widest sense is inseparably connected with virtue and piety, and consequently a 
a positive blessing. It therefore follows that we are not pursuing. the right kind of knowledge. It is too local and partial. The mind must be properly balanced by knowledge of principles, it must be expanded into that wide range of science which enables man to see all his moral and intellectual relations in their true light. It is not sufficient that he learns the relations of material things - that he subdues nature to his will. By his power over the elements, by the use of electricity, galvanism and steam, he may bring all parts of the earth into closer communication. These powers, aided by mechanical knowledge, and applied in various ways, may abridge human labor a hundred fold. The free press may disseminate this knowledge through the world; but should we thus go on attempting to improve our physical condition without duly attending to the higher laws of our moral and divine relations, what can be expected but that retrograde movement, in this respect, which all pretended refined nations have experienced, and which has ended, or must sooner or later end, in their final destruction. This kind of knowledge is useful and highly important in its place; and so is all that which is generally called practical among men, such as knowledge of facts in relation to worldly business. Our physical condition must have its proper share of attention. But who does not see that this kind of advancement may be made to usurp the place of more important interests. Teach man the higher principles of science, let him see clearly their immediate connection with his real interests, and his physical advantage will be rightly understood. He will make them subservient to his highest interests both in this world and in the world to come. Neglect these, and his physical advantages serve but to augment his misery and secure his ruin. The boasted utilitarian principle, the reliance on what is called matter-of-fact and experimental knowledge, is the legitimate result of the Baconian Philosophy, or as it is generally called, the Inductive System. Its foundation is laid in the observation of facts - its facts are proved by experiments, and the correctness of its experiments is tested by the external senses; for these senses are, according to his Philosophy, the 
foundation of all psychological, as well as physical knowledye. Thus the imperfect and variable organs of sensation are made to supercede the eternal and unchangable laws of science. It is true the mind takes cognisauce of the material world by the aid of these senses; but they are connected with the lowest extreme of the intellect - the perceptive faculty; hence all the testimony received through this source must, before it can be relied on, be examined by the reasoning faculty - by the fixed laws of science, as developed by the constitution of the mind itself. The reasoning power is the highest extreme of intellect, and in accordance with the true systern of science, which reveals the law of subordination; the highest always supercede the lowest branches. This will be understood in regard to the mind by showing the systematical arrangement as it is developed by its relation to matter. The first division includes the perceptive powers, the second, the retentive power; the third, the reasoning power.* The perceptive faculties are the lowest - the first developed; they predominate in the infancy of individual life, and in the earliest period of the luuman racc. In the savage state, perception predominates over reason. The savage believes his senses. He says the world is flat, and the sun moves round, and actually rises and sets. This is the testimony of the external senses, which it is the office of reason to correct, and reason is predicated on the intuitive principles of mind, from which there is no appeal - therefore, it is clear that induction is useful only when rightly applied. But without deduction it is a baseless fabric. Man need not sin in this world, and then pass to the next, in order to prove by experiment that $\sin$ is necessarily connected with punishment. He knows this from the laws of science. IIe wants no facts brought forth by the inductive principle of experiment to prove it. In this as in all other cases the principles of mind are corroborated by divine revelation. Religion stands between the mental and divine departments. The law of duty is implanted in the moral constitution of the mind. Religion re-

\footnotetext{
* These divisiuns show the developement of the intellectual powers in relation to the material world, while the analysis of intellect, given in the Synopsis shows their arrangement in the mind, in its more mature stato.
} 
cognizes and amplifies this law, showing its connection with the welfare of the soul. This law of duty recognizes the relation of $\sin$ and punishment, and of virtue and happiness, and points out three states. The first, a state of blessedness, the heavenly state; the second, a state of probation, or earthly state; the third, a state of punishment, or the world of woe, a state of death to the soul. This last mentioned state is the lowest extreme, and consequently, the opposite of the heavenly, to which the true progress of the mind, in its upward ascent, would lead: it being in this case guided by the laws of science, while a downward course towards the other extreme would as surely result from an attempt to evade or disregard these laws. The worm, obedient to the laws of his nature, spends a part of his life in preparing a covering of a material which is a non-conductor of electric force.In this tomb he envelopes himself, and thus retains the feeble galvanic force, which sustains a kind of vitality while he passes through the shades of death, and ensures himself a resurrection into a higher world of life and light and happiness. He is no longer confined to the dust on which he was doomed to crawl in his less perfect state of being, but soars aloft in the pure light of day, and wings his way over flowery meads and widening scenes of joy.

Now, had he disregarded the laws of his nature, and neglected to prepare himself for the change of death, he must have died as he had lived, unprepared, and fallen to the lowest extréme of his nature, that of inanimate dust. So it is with man - if he disobeys the laws of moral science and neglects to prepare that guard for his soul which virtue and piety alone can secure, and which shall save his soul alive as he passes through the ordeal of death, and becomes prepared for a glorious resurrection. If he neglects this preparation, then he must, whenever death overtakes him, fall to the lowest extreme of the mental state, and insure an entire separation from the upper world. The animal dies a physical death, the man a spiritual death, this is a state of woe, it is called everlasting death. The Philosopher should stop here, and leave the description with divine revelation. All we know from reason is, that it is a state consequent on sinful- 
ness, and that the degree of punishment will be proportionate to the amount of sin committed. (There is a lowest hell as well as a highest heaven.) This state, as we have already shown, is the consequence of an aberation from the progressive laws of science, and admits not of extensive explanation.

Let us now pass from this lowest state to the next in order, the probationary state. Here the laws of science teach us that the true course is that of progression from a less to a more perfect state; and if we continue in such a course, we shall pass on to the divine state; nothing is necessary but a strict compliance with these laws. The animal just mentioned obeys the laws of his physical nature by impulse - by mere instinct; - and so did man, in the primeval state of innocence, obey the moral law of his spiritual existence by impulse; he knew not even that disobedience was possible; he knew not evil; he, therefore, had no knowledge of the difference between good and evil, until the falsehood was uttered by the evil one, "In the day ye eat thereof ye shall not die." Here all the difficulty arises. The error here promulgated has been in the world ever since. Man ignorantly thinks he can evade the laws of science.

God has implanted the great principles of moral and religious science in the constitution of our minds so firmly that the ordinary exercise of reason clearly developes them, giving a standard of right which no circumstances of education can destroy. It is intuitive and invariable as any law of nature. Thus man is not excusable for any sinful act. It is no excuse for him that he is ignorant of truths which are so completely within the reach of the most ordinary capacity. Let it be every where understood, then, that the laws of science are the laws of God, and that every attempt to evade them must prove unsuccessful, that it is a sin - and that the connection between sin and punishment, as cause and effect, is as certain as that between fire and heat, for that very law which requires compliance, makes punishment the necessary consequence of all attempts to evade it. He that sins with the hope of escaping punishment is no wiser than he who throws himself into a glowing furnace with the expectation of escaping uninjured. It has been above stated that true knowl- 
edge of science is inseparably connected with virtue and piety, and consequent happiness, for this knowledge which teaches the laws of science teaches the necessity of complying with them.Now, althongh ignorance is the cause of sin, it affords no excuse since knowledge is clearly within our reach.

What am I ? What is my destiny? And what are the things around $m e$ ? are the inquiries of every well regulated and well informed mind, as it goes forth upon the works of creation. Such reflections are not, as the dull sensualist would claim, the result of a morbidly sensitive mind, nor a merely romantic imagination, but spring from the spontaneous operation of reason-controlled thoughts. The sublime truths and hallowed beauties, which dwell far beyond the range of visible and tangible things, are reflected down from heaven to the purer spirits on earth, and the mind that seeks earnestly shall find treasures in the depths of science which belong not to mortality.

It is true that man in the first and lower elements of his being is endowed with the power of external sensation, which he holds in common with the lower orders of animals; and it is also true that his mental organism receives its development and education in part through this channel, aided by its own super-combined laws. These senses are the portals through which the mind holds communion with nature. All material light, beauty, form and sounds - all earthly things continually present their offerings at the shrine of spiritual existence; while they in their turn receive new attributes of truth and harmony when clothed in the vestments of spiritual life - the source of higher knowledge. Here let us ascend from the external senses which belong to corporeal existence and give knowledge of nature, to a consideration of the higher sense of mind. The former are often deceptive and imperfect; a ray of light does not always present its object to the eye in its true direction; all ears do not hear the same sounds, nor in the same direction; nor do all eyes distinguish the same colors. All celestial bodies appear to be more elevated than they really are, owing to the refractive powers of the atmosphere 
which bend the rays of light towards the earth; thus stars ap pear above the horizon after they are set. Terrestrial objects often appear elevated, depressed, or double, in consequence of the different strata of atmosphere, possessing different degrees of density, caused by difference of temperature. Many of these difficulties in the way of truth which owe their origin to these last mentioned causes máy be removed. But there are constitutional defects in the organs of external sense which can never be entirely removed; this is not the case, however, with the mental sense, for there is not a rational man on earth who, if rightly educated, could not perceive all the elementary truths of intellectual and moral science. The truths of geometry are alilie perceived by all minds that perceive them at all. Our duty to God and our fellow beings is so clear to all minds that if all the millions of human beings on earth could have the same degree of knowl. edge, they would agree in every case relating to moral and religious duty, so that there would not be found one dissenting voice. Thus we perceive that the mental or spiritual sense is founded in unchangable laws of psychological science, and after it is once developed, may exist independent of the external senses which depend on a material organism, and are destined to share in its dissolution; like the flower that dies with the plant that sustained it, while the spiritual sense is reserved as in the seed that survives the change of death.

Having established the high powers and indistructibility of the mental sources of sense, we perceive that a new world is brought to view, without which nature would lose all her charms and become a lifeless corpse - a body without a soul; and there are those who have wandered far away into this new region without knowing how they got there. They see new beautics and harmonies, the source of which they do not fully comprehend. Like the immortal Socrates, charmed with his distant and imperfect view of a pure system of moral truth, or like the holy men of oid inspired with the gift of prophetic endowment, they feel what they cannot explain to other minds. They become transcendentalists, and their writings become incomprehensible to the ordinary reader. 
A proper survey of Pantonomic science cannot fail to establish a clear view of the relation which exists between the physical and mental worlds, and present the harmony of their laws in such light as to render the subject highly interesting and instructive.

We will now ascend still higher, and show that the mind has higher relationship, and may be brought into harmony with the divine world, where there is a higher sense developed. In the true synthetic order and progress of knowledge, we proceed upward from the physical sense to the mental, and from the mental to the divine sense, which is inspiration.

By the natural eye, we perceive but few objects immediately around us, but in imitation of the mechanism of this organ, the mind prepares and arranges instruments of telescopic power, by which distant and unseen worlds are brought to view; the light of innumerable orbs and systems in the far regions of space is brought down to us and linked with our own material being by kindred ties of relationship. And thus it is in the mental world; psychological science presents a scene of spiritual harmony and truth ; and the whole material world, when its laws are revealed, becomes one great system of telescopic media to the mental vis. ion, by which the light, the truth, and the harmony of the heavenly and divine world shed down their holier influence on the soul of man, and raise him up to that elevation where mental and divine knowledge-where wisdom and piety are united.

Let us now descend again to the relation between mind and nature.

Every degree of corporeal sensation, has its counterpart in the affective, (or, as they are called in the synopsis,) sensitive powers of the mind. To light and darkness, belong joy and sorrow ; to symmetry and deformity, belong love and hatred; to harmonious and discordant sounds, belong courage and fear; and thus every emotion of the mind is made up of these affections, either singly or variously combined.

The charms of morning skies and evening shades, with all their intervening changes; the rejuvenescence of spring, and the sombre hues of fading autumn, are but the elements of the poetry of 
nature, reflected upon the mind through the medium of sound, color and form. From the monotone of the funeral dirge, to the highest notes of joy; from the dark pall that covers the dead, to the light and varied colors of youthful gaiety-each degree links with a sympathetic chord in the affections of the mind. And all the higher intellectual impressions of geometrical or mathematical truths, have their counterpart in the regular and invariable laws of all the processes of nature-here mind and nature harmonize, all is order, even that which we call pleasing variety, is nothing but extended order and uniformity. Take for instance, the science of music, and we find it is this very law of uniformity which submits to the strictest rules of mathematical formulae, that creates all the high interest we feel in listening to it, and without which it would be neither science nor music, but mere discord:

Let us now descend to the lowest extreme of nature, and take a glance at the elements of matter and motion.

Matter in its primary state is divided in to oxygeneous, ethereal and hydrogeneous elements. The ethereal or neutral element which pervades all space, serves only as a medium for the communication of mechanical motion, while the two extremes, the oxygeneous and hydrogeneous, by their relation to each other, become the only agents through which choloric produces its effects in carrying on all the works of material creation. Taking these extremes as the true data, we have the following series: 1st Oxygen, 2d Chlorine, 3d Fluorine, 4th Iodine, 5th Tellurium, 6th Azote, 7th Carbon, 8th Sulphur, 9th Phosphorus, 10th Boron, 11th Sillicon, 12th Metals, 13th Zinchona, 14th Glacina, 15th Alumina, 16th Alkaline Metals, 17th Hydrogen. These intermediate substances, placed between oxygen and hydrogen, partake more or less of the nature of the extremes according to their situation in the series, whether we consider them as actual compounds of them, or as mere simple elements. They are arranged here according to the resemblance of their properties, the same as we would arrange the different shades between the extremes of prismatic colors, without stopping to inquire whether all those substances called elementary are included in the range, 
or whether many which are included may not be further analyzed by increased galvanic force; for this would not affect the present theory, as they would still show that they belonged to the same series; as do the different colors when subdivided into lesser shades.

If oxygen gas is 16 times heavier than hydrogen, we may infer that one atom of the former occupies, under the same temperature, (if the size be affected by temperature,) just one 16th of the space occupied by the latter in proportion to its real amount of matter, and that the series depends on the gradation of size in the atoms or original particles of the different elements. Here we have the first series in the secret operations of nature. It depends on the size of atoms. The second series ranges from transparency to opacity, and depends on the arrangement of atoms in the mass. The third series ranges from the aeriform to the solid state, and depends on the form of atoms.

We can change a transparent substance into an opake state, - merely by increasing its thickness, and without, in the least, changing its composition, and we can also change the solid form to the liquid or aєriform, by an increase of temperature, without apparently changing the chemical composition ; it is evident that these properties depend on calorific motion and mechanical arrangement. But the original gases have not, by any agency yet known, been thus transmuted into each other; we have never seen oxygen expanded by heat into hydrogen, nor have we seen the latter condensed by cold or pressure into oxygen; and yet it is not certain that such an effect cannot be produced. It may be that their original difference depends on their different degrees of susceptibility to calorific motion. Oxygen, by the application of heat assumes the character of a conductor of electricity, a property which belongs to hydrogen and not to itself in the normal state. Expand oxygen until its volume equals that of an equal weight of hydrogen, and what are their properties in relation to each other? How are we to learn? The moment they are brought in contact, the heat of the former is transferred to the heat of the latter, its volume is expanded as far beyond its ordin- 
ary state, as the other gas is beyond is own. This only proves that their union takes place when both are under the same degree of motion or temperature; and, it may be thought nothing is gained by the experiment. But have they shown precisely the same character in relation to each other at this degree of temperature, that they would under a different degrec? May not the intensity of action resulting from their relation decrease as we arise from a given point of temperature, by some definite law of proportion between temperature and intensity of action, until all power arising from their relation ceases, thus destroying all chemical action by their homogeneous character? And again, is it not probable that as we decrease the temperature and descend below this given point, a similar law of decreasing action prevails, until we arrive at a point where all chemical action ceases. Here is a great series formed; or rather, two series of action proceeding from a medium point in opposite directions, until they terminate in two extremes, uniting in a certain result, viz., an entire destruction of an organized material world; the one producing a complete state of rest in every atom of matter, resulting from an entire absence of calorific motion, the other such a high degree of this motion, as to keep every atom of matter at such a distance from each other as to prevent their relation and union, and consequent organization.

Here we have data from whence to commence our inquiries into the origin of the solar system,-commencing with the three original elements in an uncombined state as the occupants of space or some part of space, and constituting that chaotic state of the substance of the heavens and the earth which God created before he said, "Let there be light." Now it is evident that matter must have been in one or the other of the extreme states of motion or rest which I have pointed out, for it could not occupy a place between them, that being the present state of action. It could not have been in the state of the active extreme, for intense calorific motion produces light, and light in this first state of matter did not exist, for God had not yet called it into existence. Besides, we have an idea independent of this proof from Scrip- 
ture, that as space may exist without matter, so matter might exist without motion, and that motion was the last principle originally introduced. Therefore it may be inferred that calorific motion was applied when the light was introduced, and in such a degree as was calculated to carry on all the subsequent operations of nature, including the formation of the solar system and all the organized bodies attached to the planets.

From the above considerations it is evident - 1st, that a proper degree of calorific force applied to two substances belonging to the oxygenous and hydrogenous extremes of the elemental series when in contact, causes them to unite in certain proportions, and by this union produce compounds differing from themselves in property; and 2d, that this same degree of power applied to two or more substances belonging to the same extreme, causes an oppositc. effect - a repulsion or separation of atoms. But we have already shown that another series may exist by which this calorific force becomes, at one of its extremes, so intense as to destroy this last series, and to hold both kinds of atoms belonging to the two extremes of oxygen and hydrogen in entire separation; that is, in the occupancy of the greatest amount of space, while the opposite extreme of this series being that of entire absence of calorific motion, leaves the atoms of all elements in a complete state of rest, (the source of attraction,) and consequently occupying the least possible amount of space in the mass, for it is certain that atoms of matter require more space when in relative motion than at rest. Therefore calorific motion once applied to matter, becomes a self-compensating force - the cause of composition, decomposition and re-composition of bodies. A moderate degree of temperature is sufficient to cause the elements of a galvanic battery to unite, and the oxidation thus produced ultimately developes intense motion, sufficient to decompose the hardest compound substances, the elements of which may again be united by the aid of that moderate degree of temperature or heat which first served to put the battery in motion and keep up its power.

Under a sufficient degree of heat in the animal body, the oxygen of the atmosphere coming in contact with the hydrogeneous 
elements, supplied by the blood, in the lungs, unites with them, producing that moderate degree of warmth, arising from the slow combustion which continues through life. Thus, a power first received from another being becomes the cause of a second power - the union of elements - chemical action, and thirdly, consequent coutinued evolution of animal heat - the blood having received its hydrogeneous properties from the food in the stomach - passes to the lungs - receives an amount of oxygen, a part of which unites in producing the necessary degree of combustion, and a part unites with the globules of the blond - passes to the heart - excites mechanical movenent, which re-acts upon the fluid, and becomes a secondary cause in aiding the general circulation - the blood still retaining its oxygen, passes to the brain, where it comes in contact with and forms a part of the nervous aperatus ; and here another union of elements takes place in consequence of the oxygen carried there by the blood, and thus evolving a sufficient quantity of galvanic force to produce all the powers of corporeal sensation.

It has been observed that the mineral kingdom is organic. Our earth in its general properties presents to view an organized body, the first divisions of which are solid, liquid and aeriform. The aeriform, or gaseous, is the first in the order of creation. Our atmosphere is a vast ocean surrounding the earth, and extending 50 or 60 miles from its surface. At the bottom of this ocean, we live, move and have our being, like submarine animals at the bottom of the aqueous ocean; so that we live in, instead of being on, our planet. The liquid state is the next in order of creation. It is beneath and around us in the form of water and vapor. The solid state is the last in the order of creation, and is beneath our feet.

All the primary operations of nature are carried on by the effects of calorific motion through the medium of size, form and arrangement of atoms of matter.

Hence we may infer that the vis vitc, the highest principle of life, that power by which man and all other animals live, is produced by Thermo-galvanic force; and that the vegetative princi- 
ple which belongs to plants as well as animals, depends on Galvano-electric force, while chrystalization which belongs to the mineral kingdom, and extends up through the vegetable and animal kingdoms, depends on Electro-magnetic force.

These three forces arise from one and the same cause, viz., the combination of oxygeneous and hydrogeneous substances, ${ }^{*}$ under a sufficient degree of previous calorific motion to cause their action, and differ from each other only, in being the result of more complicated arrangements, as we pass upward from the most simple in the mineral to the most complicated in the animal organization.

In explaining the elements of motion, we must go back to the first principles. All bodies in the solar system, as well as all the atoms in the solid mass, while operated upon by caloric, move in orbits consisting of three motions combined, the centrifugal, centripetal and tangental.

If a fire be kindled in ab open space on the surface of the earth, oscilation is the immediate result; the rarified air is propelled upward, passes off and returns in a more dense state below. Now if this fire was kindled up, like the sun, in a place far removed from all other bodies, the repulsions and attractions, that is, the oscilations, would take place in all directions from and towards the central source, every body floating in space, within the reach of its influence, would move from it and then return, not in direct lines, but in eliptical orbits round the centre, approaching towards circles in proportion to the density of the body. Thus there are two extremes between which all bodies move, for there can be none so dense as to move in a circle, and none so rare as to move in straight lines to and from the centre. Light and heat move in straight lines, therefore they are not bodies nor atoms, but consist of motion communicated from par ticle to particle of the ethereal medium through which they pass, producing a succession of minute consecutive oscilations. (Here we may infer, hypothetically, that heat depends on the length, light on the rapidity, and chemical rays on the width, of these

\footnotetext{
- These extremes constitute, probably, the ultimate source of the sexual relations in plants and animals.
} 
oscilations.) No body, under the influence of calorific motion can move in direct lines to and from the centre of motion; for the moment its rarity equals that of the medium through which it passes, it must cease to be a distinct body and become homogeneous with that medium.

Now suppose this ethereal medium to possess the same degree of density every where, whether in general space or between the atoms of solid bodies; then we have a fixed law of proportion between the density of an atom or a body and the eccentrity of the elipse of its orbit in this medim, and we may learn the exact density of every body in our solar system as soon as we know the elements of their orbits.*

From this hasty view of the laws of motion, it appears evident that calorific motion is the primary cause of all effects in the material world. There could be no motion without it. "God said, Let there be light, and there was light." This light arose from the application of caloric to the oxygeneous and hydrogeneous elements in an uncombined state. Here this universal agent was introduced-the sun was lighted up-and from that moment it went on, aided by the laws of mechanical and organic motion, to the complete formation of the present material world, under the guidance of Him who first introduced it.

The rotatory motion of storms, whirlwinds, and waterspouts, is the result of this oscilative force modified by mechanical causes, and running through every degree of elipticity of gyration, and every degree of elevation from a horizontal to a perpendicular whirl, depending on the alternate rarification and condensation of matter-the ever-beating pulse of nature.

\footnotetext{
* According to this law of motion a comet must be extremely rare, and especially so when near the sun, for it moves in an extremely cecentic elipsis. Many of them must be less dense than our atmosphere: and from the laws of light here developed, we perceive that the comet's tail does not consist of matter, but is nothing more than the sun's light deprived of its calorific and red rays while passing through the comet; which accounts for the cold weather expcrienced during a cometary visit, as well as the stream of whitish light called the tail.

It also appears from this system that our earth, and all other bodios in the solar system, must increase in density from the earliest period of their existence till their final dissolution; and therefure that their orbits must be tending towards perfect circles; and the time occupied in each of their successive revolutions slowly diminishing.
}

[The term elipeis, is used in this work to designate orbits describing conic sections.] 



$$
\begin{gathered}
Q \\
173 \\
L 62
\end{gathered}
$$


UC SOUTHERN REGIONAL LIBRARY FACIUITY

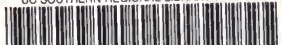

A 0006589717 
